\title{
The business case for One Health
}

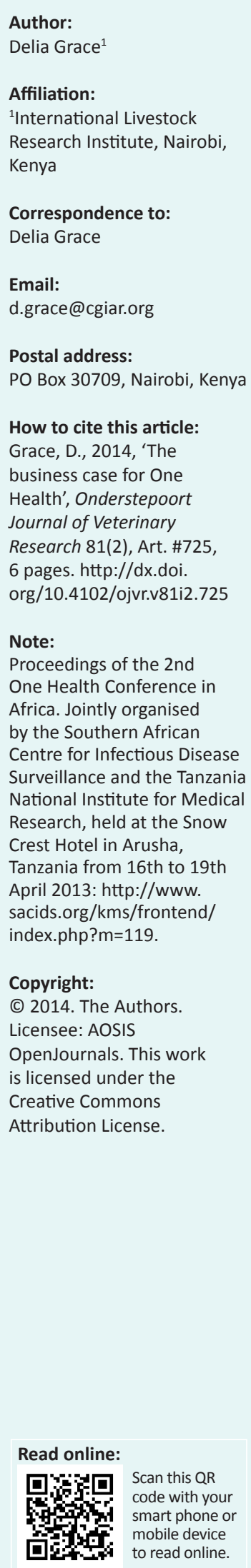

This article outlines a pathway to develop the business case for One Health. It describes the origin and development of One Health and then identifies five potential areas where One Health can add value and reduce costs. These are: (1) sharing health resources between the medical and veterinary sectors; (2) controlling zoonoses in animal reservoirs; (3) early detection and response to emerging diseases; (4) prevention of pandemics; and (5) generating insights and adding value to health research and development. Examples are given for each category along with preliminary estimates of the potential savings from adopting the One Health approach. The literature reviewed suggests that one dollar invested in One Health can generate five dollars worth of benefits and a global investment of US $\$ 25$ billion over 10 years could generate benefits worth at least US\$125bn. Conservation implications: the time has come to make the bigger case for massive investment in One Health in order to transform the management of neglected and emerging zoonoses and to save the lives of millions of people and hundreds of millions of animals whose production supports and nourishes billions of impoverished people per annum.

\section{Introduction}

This article is based on an invited keynote presentation given at the Southern African Centre for Infectious Disease Surveillance (SACIDS) One Health $(\mathrm{OH})$ conference held in Arusha, Tanzania in April 2013 (Grace 2013). It draws on the experiences of the International Livestock Research Institute (ILRI) that were gathered through a number of $\mathrm{OH}$ and Ecohealth (EH) projects over the last decade and incorporates findings from a literature review.

$\mathrm{OH}$ is a broad movement that recognises the fact that human, animal and ecosystem health are interdependent and that multidisciplinary collaborations are often necessary in order to attain optimum health solutions. The article was motivated by a growing consensus that although $\mathrm{OH}$ is well understood and appreciated it has yet to gain large-scale traction in the medical and donor communities.

As of 2013, OH is endorsed by global standard makers, namely, the World Organisation for Animal Health (OIE), the World Health Organization (WHO) and the Food and Agriculture Organization of the United Nations (FAO), as well as being supported by the World Bank. The last decade has seen a large number of conferences and a series of international inter-ministerial meetings with a focus on avian and pandemic influenza. There are currently around 20 universities offering $\mathrm{OH}$ graduate degree courses, including institutes in America, Africa, Europe and Asia. The OH Initiative acts as a clearinghouse for information on $\mathrm{OH}$ (http://www.onehealthinitiative.com), the One Health Global Network operates a web-portal (http://www.onehealthglobal.net/) to facilitate communication and the One Health Commission also shares information (https:// www.onehealthcommission.org/). The EcoHealth Journal publishes on EH and articles on both $\mathrm{OH}$ and $\mathrm{EH}$ have appeared in other major epidemiology and infection journals. In addition, 2012 saw a major new publication on EH (Charron 2012), updating the classic by Lebel (2003).

However, despite this large and growing body of evidence supporting the usefulness of $\mathrm{OH}$, the great majority of medical education, clinical practice, ancillary services, development programmes and research continue to operate within disciplinary boundaries. This lack of uptake of $\mathrm{OH}$ was attributed initially to there being insufficient evidence to convince practitioners and decision makers. However, notwithstanding the growing evidence for $\mathrm{OH}$, the organisation of health by sectors still persists to a large extent.

At least partly in response, attention has turned to the economic justification of $\mathrm{OH}$, with an important article by the World Bank setting out the potential savings from investing in $\mathrm{OH}$ in order to prevent pandemics (World Bank 2012). Yet others argue that promotion of OH requires 
an understanding of how major shifts in health policy and practice occur, as well as how the ability to influence opinion shifts. Many models exist for both understanding and influencing policy change and most of these involve, either implicitly or explicitly, a 'theory of change'. These models recognise that evidence is only one part of policy influence and that positive influence of policy is highly dependent on context (Jones 2011).

This article discusses the process of building a compelling business case for $\mathrm{OH}$ in the context of a theory of change for adoption thereof. We first discuss various definitions of $\mathrm{OH}$. Next, we present a 'Big Five' framework for categorising $\mathrm{OH}$ problems and related interventions. We then provide estimates from the literature on the costs of the $\mathrm{OH}$ problem as well as the likely costs and benefits of $\mathrm{OH}$ interventions, drawing on a small number of key articles and reports. Finally, we provide recommendations for building a convincing business case for One Health.

\section{Background and definitions for One Health}

That human, animal and environmental health is related has been recognised throughout the historical development of medicine on all continents (Zinsstag et al. 2011). In most indigenous and historical medical systems, animal and human diseases are conceptualised as having similar causes, manifestations and treatments. But as medicine developed into a profession, a separation grew between those who treated humans and those who treated animals, with human doctors given higher status. (That being said, entry to veterinary schools in several countries in recent decades has been more competitive than entry to medical schools.) In the 19th century, European medicine became the dominant paradigm and entrenched the largely sectoral approach wherein human and animal health was separate disciplines and there were only weak connections between ecology and health.

The 20th century saw three major movements, all of which contributed largely to current thinking on $\mathrm{OH}$. The first was the concept of 'One Medicine' which arose out of the work of Calvin Schwabe with the Dinka in Sudan (Zinsstag et al. 2011). The second movement was 'Ecosystem Health' or 'Ecohealth'. This adapted thinking from ecology and environmental management to the improvement of human health and wellbeing. Important early work on mercury contamination in the Amazon basin was supported by the Canadian International Development Research Centre, which has continued to support research and programmes and to develop the approach (Charron 2012). The third movement, which took the title of $\mathrm{OH}$, arose because of increasing concern of disease emergence at the interface between animals, humans and ecosystems (Nabarro 2012). This was triggered by a series of disease emergences of global importance in the 1990s, including severe acute respiratory syndrome (SARS), avian influenza and West Nile virus and had strong participation from veterinary and, to a lesser extent, human public health.
One Health can be defined as the collaborative effort of multiple disciplines to attain optimal health for people, animals, and our environment. Ecohealth has been defined as systemic, participatory approaches to understanding and promoting both health and well-being in the context of social and ecological interactions. Both definitions emphasise multidisciplinarity and the importance of agriculture and ecosystem-based interventions in order to attain health goals. The first decade of the 21st century saw an increasing convergence of One Health and Ecohealth, leading to the development of a broader discipline which incorporates infectious and non-infectious disease, epidemiological and ecological methods and both disease control and development (Zinsstag 2011).

The boundaries of $\mathrm{OH}$ and $\mathrm{EH}$ are fuzzy, with interpretations differing between groups. For example, the Stone Mountain Working Group felt that $\mathrm{OH}$ initiatives should address human, animal and environmental health simultaneously. On the other hand, the EcoHealth Journal (http://www. Ecohealth.net) publishes not only on zoonoses but also on diseases that affect only wildlife (such as bat white-nose syndrome). The disease theme of the Consultative Group on International Agricultural Research (CGIAR) Research Program on Agriculture for Nutrition and Health focuses on food-borne diseases and zoonoses but also goes beyond zoonoses and occupational hazards to consider such things as obesity and anthroponotic but agriculture-related diseases as being $\mathrm{OH}$ issues (e.g. malaria, which is linked to irrigation but is not a zoonosis).

This article considers as $\mathrm{OH}$ both those interventions and actions which address diseases that are either actually or potentially common to both humans and animals. This includes toxicosis due to aflatoxins, heavy metals or other injurious substances; resistance to antibiotics, parasiticides or other drugs used to treat both humans and animals; classical zoonoses such as brucellosis and tuberculosis; and emerging diseases such as avian influenza which are either zoonotic or potentially zoonotic.

\section{Framework for categorising One Health problems and interventions}

Several reviews suggest areas where $\mathrm{OH}$ is most likely to make a difference (Rushton et al. 2012; World Bank 2012). This article identifies a 'Big Five' of key areas. For each, the review provides a brief description of the area for collaboration, cites examples and calculates estimates on costs averted and benefits obtained by an $\mathrm{OH}$ approach.

\section{Key Areas \\ Joining up health resources: Sharing health resources between sectors}

Sharing health resources across human and veterinary health sectors would appear to be an easy win. This is especially the case for laboratory facilities as the majority of pathogens and chemical hazards are common to both humans and animals. 
Joint laboratory facilities are particularly important in developing countries where scarcity of human and financial resources challenge the sustained operation of laboratory resources. A second area is shared education resources; much of the pre-clinical curriculum is common to both human and veterinary medicine and there are similar overlaps in many paraveterinary and paramedical curricula. Disciplines which work at a scale much higher than the individual patient (e.g. epidemiology) or much lower (e.g. molecular biology) use essentially the same methods for both humans and animals and can easily combine forces. There are already some courses which target both veterinarians and medical doctors, for example joint Masters degrees and the integrated courses delivered by the South African Field Epidemiology and Laboratory Training Programme (SAFELTP). Surveillance is a third area where there are obvious advantages to systems which are at least joined up and possibly integrated. Several of the most important surveillance systems are 'One Health'; these include ProMED (http://www.promedmail.org), HealthMap (http://healthmap.org/en/) and the Global Early Warning System (GLEWS, http://www.glews.net). A fourth possible area for joining forces is disease control, especially in remote, livestock-keeping communities. Linking livestock vaccination with vaccination of children has been piloted in Chad in communities where the majority of livestock, but no children, were vaccinated (Schelling et al. 2007).

Estimating the benefits of collaboration across medical and veterinary services is challenging. The operation of a joint laboratory in Winnipeg is estimated to have reduced overall costs by $26 \%$ (World Bank 2012). The World Bank (2012) estimates a $10.0 \%-27.5 \%$ saving across a range of joint services for avian influenza control. The campaign in Chad suggested that combining both human and livestock vaccination reduced overall costs by 15\% (Schelling et al. 2007). We assume that both of these are on an annual basis.

Human health expenditure in developing countries was estimated at US $\$ 521$ billion in 2012 (IHME 2012). Estimations for veterinary health expenditure are less solid, but combining data from a number of studies suggests an expenditure of US\$1bn - US\$2bn on public animal health services in developing countries (Bonnet et al. 2011; Gallacher 2007; OIE 2009). Based on the studies cited above, it can be assumed that joint operations can save around $10 \%$ of the combined medical and veterinary budget devoted to those functions which are amenable to sharing. Best available evidence suggests that laboratories, education and management of zoonoses are services which can be shared and that these constitute $5 \%$ of the human health budget and $40 \%$ of the veterinary health budget (Eurostat 2012). This implies that the total savings of joined-up services could be US\$2.68bn per year. Given estimates of the cost of collaboration, net savings of around US $\$ 3$ bn imply gross savings of around US $\$ 4 \mathrm{bn}$ per year.

\section{Controlling zoonoses in animal reservoirs}

Historically, most major zoonoses that have been controlled successfully have concentrated on the animal reservoir. This includes diseases such as brucellosis, tuberculosis, rabies, salmonellosis, cysticercosis, trichinellosis and others which have been controlled successfully in many countries.

A large number of economic analyses have been conducted in order to compare the costs and benefits of control and/or localised elimination of zoonoses. Table 1 summarises some representative studies. Economic assessments conducted after a control campaign is finished give results comparable to ex ante assessments, which suggests that ex ante assessments are credible. (However, this may be less true when animal health services are weak.) Whilst a wide range of benefit-tocost ratios are reported, all the literature reviewed showed a positive ratio. The median ratio of benefits to costs was around four to one with human health benefits at least equal to animal health benefits and often greater.

This approximate, but relatively robust, estimate allows an assessment of the costs and benefits of controlling zoonoses in developing countries. A recent study estimates that around one in seven (14\%) livestock in developing countries

TABLE 1: A selection of studies showing the costs and benefits of control of zoonoses.

\begin{tabular}{|c|c|c|c|c|c|}
\hline Disease & Perspective & Country & Costs considered & Benefit-to cost-ratio & Reference \\
\hline \multirow[t]{5}{*}{ Brucellosis } & Ex ante & Nigeria & Livestock only & 3.2 & Cited in McDermott, Grace and Zinsstag (2013) \\
\hline & Ex ante & Mongolia & $\begin{array}{l}\text { Human health and } \\
\text { livestock }\end{array}$ & 3.2 & \\
\hline & Expost & Czech Republic & Livestock only & 7.1 & \\
\hline & Expost & England \& Wales & $\begin{array}{l}\text { Human health, } \\
\text { livestock and trade }\end{array}$ & 2.2 & \\
\hline & Expost & England \& Wales & Livestock only & 1.1 & \\
\hline Schistosomiasis & - & - & - & 6.0 & Grey, Williams, Li and McManus (2008) \\
\hline Echinococcosis & Ex ante & Tibet & $\begin{array}{l}\text { Human health and } \\
\text { livestock }\end{array}$ & 3.0 & Budke et al. (2005) \\
\hline Rabies & Expost & USA & $\begin{array}{l}\text { Human health and } \\
\text { animal tests }\end{array}$ & $3.4-13.1$ & Shwiff, Kirkpatrick and Sterner (2008) \\
\hline Bovine tuberculosis & Ex ante & UK & - & 1.71 & DEFRA (2011) \\
\hline Salmonellosis & Ex post & Finland & Human health & $\begin{array}{l}19.8 \text { for eggs and } \\
5.4 \text { for meat }\end{array}$ & Maijala and Peltola (2002) \\
\hline
\end{tabular}


each year are currently or recently infected with one or more zoonoses and that each infection reduces their productivity by around 10\% (Grace 2013). According to the FAO, the value of livestock production in developing countries was US\$639bn per year at the time of their study (FAOSTAT, 2012), suggesting that the productivity losses related to zoonoses is around US\$9.26bn per year (assuming that current losses are $1.4 \%$ and that, without these, production would be US $\$ 648 \mathrm{bn})$.

In addition to morbidity, mortality is an important cause of loss for livestock. Numerous studies on developing country livestock indicate that annual mortality is high. Otte and Chilonda (2002) provide the most thorough review (although only covering Africa) and this implies a mortality rate of $21 \%$ weighted by age and species. Assuming that half of livestock mortality is because of disease and that half the disease is a result of zoonoses (World Bank 2011), then developing countries currently lose approximately 68 million tropical livestock units (TLU) because of zoonoses (this represents $25 \%$ livestock mortality as a result of zoonoses, namely, $50 \%$ of $50 \%$ of disease-related livestock mortality). To extrapolate, assuming that the value of a TLU is US\$366, this costs developing countries US\$25bn per year. On the other hand, official reports of the OIE suggest that only around 400000 livestock units are lost each year in developing countries - a mortality rate of $0.03 \%$ (World Bank 2011). This implausibly low estimate is an artefact of under-reporting and underestimation of losses by between two and three orders of magnitude (Grace et al. 2012).

The human health costs of zoonoses are typically equal to or greater than the livestock sector losses, a trend which is becoming more pronounced with time (World Bank 2012). The aforementioned study suggested 2.2 million human deaths and 2.4 billion human illnesses a year from zoonoses (Grace et al. 2012). Using standard and conservative costs of human illness, we may assume losses of at least US\$50 billion in 2013.

This implies that the annual costs of zoonoses may be US $\$ 9 \mathrm{bn}$ in lost productivity, US $\$ 25 \mathrm{bn}$ in livestock mortality and US\$50bn from human health - rounded up to US\$85bn in all per year. Based on the studies cited in Table 1, the costs of control are typically one fourth the benefits and a control programme may extend for five to 10 years, so the US $\$ 85 \mathrm{bn}$ in annual losses could be averted by a expenditure of US\$21bn over this period. (Please note that, for simplicity, we do not consider discounting in this or other estimates).

\section{Early outbreak detection}

In the case of highly contagious diseases, rapid response is key to reducing the cost of disease outbreaks. It is difficult to estimate the costs of a counterfactual, that is, the costs that would have been incurred had response to outbreaks been more timely. However, an approximate quantification of the savings obtainable by early and efficient management can be obtained by comparing the costs of epidemics caused by the same disease in different contexts. For example, control of the bovine spongiform encephalitis (BSE) outbreak in Britain is considered widely to have been suboptimal because of a range of factors (including the novelty of the disease; lack of understanding of impacts; over-estimation of the effectiveness of control; and the wide establishment of the disease). On the other hand, when the disease was introduced to other countries, response was more rapid and effective. Canada can then act as a counterfactual for the UK and, by comparing the costs of the outbreaks in the two countries, we can estimate that if control had been as timely and effective in the UK as in Canada, $88 \%$ of the costs could have been averted (Table 2).

Contexts that affect the timeliness of control include: whether the disease is a surprise or anticipated; whether there is effective surveillance in place or not; and whether public services are well funded and well functioning or have suboptimal performance. By comparing effectivelycontrolled epidemics with poorly-controlled epidemics we estimate that well-functioning surveillance systems and timely responses may reduce the cost of outbreaks by $95 \%$.

The World Bank estimates that outbreaks have cost on average US\$6.7bn from 1997-2009 (World Bank 2011). They estimate that a US\$3.4bn investment in animal health systems per annum would support these systems so that they could function effectively and efficiently, enabling them to avert the losses incurred through delayed or inadequate response. A $95 \%$ reduction in costs amounts to US\$6bn saved per year.

\section{Pandemic prevention}

In addition to the ongoing losses from disease outbreaks, which have become the 'new normal', there is considerable concern over the possibility of a civilisation-altering pandemic or plague. These have occurred regularly but infrequently throughout history and pre-history, with the most recent example being the HIV pandemic. In a landmark study, the World Bank considers the possible impacts and costs of averting high impact but low probability pandemics (Burns, Van der Mensbrugghe \& Timmer 2008). We draw attention to their key message:

TABLE 2: Comparing worst case and better case disease surveillance and response incidents.

\begin{tabular}{lllll}
\hline Outbreak & Worse case (US\$) & Better case (US\$) & Potential loss averted & Context leading to better or worse control \\
\hline Bovine spongiform encephalitis (BSE) & UK 1994: 13 billion & Canada 2004: 1.5 billion & $88 \%$ & Known, surveillance in place \\
Foot and mouth disease (FMD) & UK 2001: 30 billion & UK 1967: 0.5 billion & $98 \%$ & Lower preparedness, easier spread \\
Highly pathogenic avian influenza (HPAI) & Asia 2004: 20 billion & Europe 2005: 0.5 billion & $98 \%$ & Higher preparedness, better systems \\
\hline
\end{tabular}

Note: Source of data originates from the literature review. 
A severe pandemic costing US\$3 trillion may occur, on average, once in a hundred years. If the investments in One Health systems are made and such a pandemic is prevented, the global expected benefits are US\$30 billion per year. Every year, an investment of US $\$ 3.4$ billion would produce an expected benefit of US $\$ 30$ billion for the international community. (Burns et al. 2008)

This expenditure of US $\$ 3.4 \mathrm{bn}$ on strengthening veterinary services would hence deliver two streams of benefits: averting major pandemics with an expected benefit of US\$30bn and improving the timeliness of response to outbreaks with an annual expected benefit of US\$6bn a year.

\section{Adding value to health research and development}

$\mathrm{OH}$ and $\mathrm{EH}$ lead to better research and disease control programmes as well as ecosystems better able to provide health as a regulatory service. Evidence for the value of $\mathrm{OH}$ and $\mathrm{EH}$ has been presented at major conferences. The most recent include: Addis (2011), Arusha (2013), Bangkok (2013), Davos (2012), Johannesburg (2011), Kunming (2012), London (2010) and Melbourne (2011). Important meetings have also been held where global health leaders endorsed the approach: these include gatherings in New York (2004), Winnipeg (2009), Bellagio (2010), London (2009), and Stone Mountain (2010). A recent review identified 41 major $\mathrm{OH}$ initiatives (Rockefeller Foundation 2011), another review showcased $31 \mathrm{OH}$ projects (VSF 2010) and a recent book sets out EH theory and practice (Charron 2012).

Whilst a large and growing body of evidence supports the hypothesis that adopting both $\mathrm{OH}$ and $\mathrm{EH}$ improves the effectiveness and efficiency of health research and delivery, the costs and benefits of adopting $\mathrm{OH}$ and $\mathrm{EH}$ as an approach to research and development are difficult to quantify. It is generally accepted that approaches which are highly participatory and multidisciplinary may have additional costs. On the other hand, participatory approaches can decrease some costs and increase sustainability. We consider this to be an important area for future research, but are unable to provide a monetary estimate.

\section{Discussion}

We reviewed the literature in order to develop a framework for assessing the benefits of One Health approaches and interventions and to summarise information on the values thereof. There is an enormous lack of information on the burden of zoonoses and much of the evidence that exists is not readily available; hence, the estimates in this review should not be considered as definitive, but rather as examples of how important benefits from $\mathrm{OH}$ and $\mathrm{EH}$ could be quantified. With this caveat, this preliminary review (presented at SACIDS 2013 [Grace 2013]) has developed initial estimates of the possible costs of zoonoses, the investments needed to control them and the benefits derived therefrom. Dollar estimates are summarised in Table 3: a US\$25bn annual investment over 10 years would generate annual benefits worth at least US\$125bn (excluding discounting). Additional benefits include saved DALYs (Disability Adjusted Life Years) which reflect the disutility of illness, as well as conserved ecosystem health regulation through reduction of zoonoses spill-over to wildlife.

Developing a comprehensive and credible ex ante assessment of the business case for $\mathrm{OH}$ and $\mathrm{EH}$ requires investment. A first step is to develop and evaluate metrics that capture the impact of zoonoses and emerging disease on human health, the livestock sector, the broader economy and ecosystem health regulation. Given the deficiencies of current official reporting systems, estimates of disease prevalence and impact are best obtained by literature review and 'groundtruthing' studies. However, long-term solutions need to involve the upgrading of reporting systems to a standard that ensures quality, transparency and reliability. This will require an appropriate incentive system to be in place in order to elicit such institutional changes amongst the key stakeholders and actors involved. Appropriate policies can help to institutionalise these processes and functions at different levels of the reporting system hierarchy.

The business case also needs to consider the options for controlling disease and their likely efficiency, effectiveness and acceptability. Developing a detailed business case covering the economic case, options, risks and priorities for One Health investments would require a multidisciplinary team with skills in epidemiology, economics and an understanding of developing country livestock sectors. We estimate that a five- to 10-person team of experts, supported by research assistants and information technology, could build the business case in one year, whilst 30 people would take just months. We believe that a credible body of evidence with regard to the costs, benefits and feasibility of control of zoonoses would stimulate investments by donors and national governments, as well as by the non-profit and private sector.

TABLE 3: Preliminary estimate of costs and benefits of One Health investments over a 10-year period with benefits and costs per year.

\begin{tabular}{llll}
\hline One Health investment area & Annual benefit (US\$) & Annual cost (US\$) & Confidence \\
\hline Sharing resources & 4 billion & billion & 21 billion \\
Controlling zoonoses & 85 billion & 3.4 billion & ++ \\
Ensuring timely response & 6 billion & -++ \\
Averting pandemics & 30 billion & ++ \\
Improving research and development & - & $\mathbf{2 5}$ billion \\
\hline Bottom line & $\mathbf{1 2 5}$ billion & + \\
\hline
\end{tabular}

Note: This table summarises the estimates provided in this article. 


\section{Conclusion}

Emerging and neglected zoonoses have often been managed sectorally, but recent decades have shown, case after case, the benefits of One Health management. The growing body of evidence suggests the time has come to make the bigger case for massive investment in One Health in order to transform the management of neglected and emerging zoonoses and to save the lives of millions of people and hundreds of millions of animals whose production supports and nourishes billions of impoverished people per annum.

\section{Acknowledgements}

This work was funded in part by support from the Ecosystem Services for Poverty Alleviation Programme (ESPA). The ESPA programme is funded by the Department for International Development (DFID), the Economic and Social Research Council (ESRC) and the Natural Environment Research Council (NERC). I also thank Lucy Lapar and Olga Jonas for their review of a draft version of the article.

\section{Competing interests}

The author declares that she has no financial or personal relationship(s) that may have inappropriately influenced her in writing this article.

\section{References}

Bonnet, P., Lancelot, R., Seegers, H. \& Martinez, D., 2011, Contribution of veterinary activities to global food security for food derived from terrestrial and aquatic animals, article presented at the 29th General Assembly, World Organisation for Animal Health, Paris, May 22-27, 79 SG/9.

Budke, C.M., Jiamin, Q., Qian, W. \& Torgerson, P.R., 2005, 'Economic effects of echinococcosis in a disease-endemic region of the Tibetan Plateau', American Journal of Tropical Medicine and Hygiene 73(1), 2-10.

Burns, A., Van der Mensbrugghe, D. \& Timmer, H., 2008, Evaluating the Economic Consequences of Avian Influenza, World Bank, viewed 11 December 2013, from http://documents.worldbank.org/curated/en/2006/06/10247442/evaluatingeconomic-consequences-avian-influenza

Charron, D.F. (ed.), 2012, Ecohealth research in practice: Innovative application of an ecosystem approach to health, Insight and innovation in international development, vol. 1, International Development Research Centre/Springer, Canada. http://dx.doi.org/10.1007/978-1-4614-0517-7 1

Department for Environment, Food and Rural Affairs (DEFRA), 2011, Bovine TB and badger control: Consultation on guidance to natural England on the implementation and enforcement of a badger control policy, DEFRA, UK.

Eurostat, 2012, Healthcare statistics, viewed 04 August 2013, from http://epp. eurostat.ec.europa.eu/statistics_explained/index.php/Healthcare_statistics

Food and Agriculture Organization of the United Nations (FAOSTAT), 2012, What's new in FAOSTAT?, viewed 04 August 2013, from http://faostat3.fao.org/home/ index.html
Gallacher, M., 2007, Economics of official veterinary services: The case of Latin America, v.04 (fourth draft), viewed 04 August 2013, from http://www.oie.int/ fileadmin/Home/eng/Support_to_OIE_Members/docs/pdf/CEMA_-_Latin_AM_ case_EN_.pdf

Grace, D., Mutua, F., Ochungo, P., Kruska, R., Jones, K., Brierley, L. et al., 2012, Mapping of poverty and likely zoonoses hotspots, Zoonoses Project 4, Report to the UK Department for International Development, Nairobi, Kenya, ILRI, p. 119.

Grace, D., 2013, One Health Approach Makes Sense in the Changing Socio-economic Landscape of Developing Countries, article presented at the 27th Annual Joint Scientific Conference and 2nd One Health Conference in Africa, 16-19 April, Snow Crest Hotel, Arusha, Tanzania.

Grey,D.J., Williams, G.M., Li, Y. \& McManus, D.P., 2008, 'Transmission dynamics of Schistosoma japonicum in the lakes and marshlands of China', PLOS One 3(12):e4058.

IHME (Institute for Health Metrics and Evaluation), 2012, Financing global health 2012: The end of the golden age?, IHME, Seattle.

Jones, H., 2011, A guide to monitoring and evaluating policy influence, ODI Background Note, viewed 09 December 2013, from http://www.odi.org.uk/sites/odi.org.uk/ files/odi-assets/publications-opinion-files/6453.pdf

Lebel, J., 2003, Health: An ecosystem approach (In_Focus), International Development Research Centre, Ottawa, Canada.

Maijala, R. \& Peltola, J., 2002, Finnish salmonella control program - efficiency and viability in food safety promotion, article presented at the 10th EAAE Congress, Zaragoza, Spain, August 28-31.

McDermott, J., Grace, D. \& Zinsstag, J., 2013, 'Economics of brucellosis impact and control in low-income countries', Revue scientifique et technique (International Office of Epizootics) 32(1), 249-261.

Nabarro, D., 2012, 'One Health: Towards safeguarding the health, food security and economic welfare of communities', Onderstepoort Journal of Veterinary Research 79(2), Art. \#450, 3 pages. http://dx.doi.org/10.4102/ojvr.v79i2.450

OIE (The World Organisation for Animal Health), 2009, Cost of national prevention systems for animal diseases and zoonoses in developing and transition countries, viewed 09 December 2013, from http://www.oie.int/fileadmin/Home/eng/ Conferences Events/sites/OIE-WB Conference_1007/OIE-Costs\%20of\%20 National\%20Prevention\%20Systems-final\%20report.pdf

Otte, M.J. \& Chilonda, P., 2002, Cattle and small ruminant production systems in subSaharan Africa - a systematic review, Food and Agriculture Organization of the United Nations, Rome.

Rockefeller Foundation, 2011, Portfolio of One Health activities and case studies, Rockefeller Foundation and Global Initative for Food Systems Leadership, University of Minnesota.

Rushton, J., Häsler, B., de Haan, N. \& Rushton, R., 2012, 'Economic benefits or drivers of a "One Health" approach: Why should anyone invest?', Onderstepoort Journal of Veterinary Research 79(2), Art. \#461, 5 pages. http://dx.doi.org/10.4102/ojvr. v79i2.461

Schelling, E., Béchir, M., Ahmed, M.A., Wyss, K., Randolph, T.F. \& Zinsstag, J., 2007, 'Human and animal vaccination delivery to remote nomadic families, Chad', Emerging Infectious Diseases 13(3), 373-379. http://dx.doi.org/10.3201/ eid1303.060391

Shwiff, S.A., Kirkpatrick, K.N. \& Sterner, R.T., 2008, 'Economic evaluation of an oral rabies vaccination program for control of a domestic dog-coyote rabies epizootic: 1995-2006', Journal of the American Veterinary Medical Association 233(11) 1736-1741. http://dx.doi.org/10.2460/javma.233.11.1736

VSF (Veterinarians without Borders/Vétérinaires sans Frontières), 2010, One health for one world: A compendium of case studies, Veterinarians without Borders/ Vétérinaires sans Frontières, Canada.

World Bank, 2011, World livestock disease atlas: A quantitative analysis of global animal health data (2006-2009), World Bank, Washington, D.C., viewed 09 December 2013, from http://documents.worldbank.org/curated/ en/2011/11/15812714/world-livestock-disease-atlas-quantitative-analysisglobal-animal-health-data-2006-2009

World Bank, 2012, People, pathogens and our planet: The economics of one health, World Bank, Washington, D.C., viewed 09 December 2013, from http:// documents.worldbank.org/curated/en/2012/06/16360943/people-pathogensplanet-economics-one-health

Zinsstag, J., Schelling, E., Waltner-Toews, D. \& Tanner, M., 2011, 'From one medicine" to "one health" and systemic approaches to health and well-being', Preventive Veterinary Medicine 101(3-4), 148-156. http://dx.doi.org/10.1016/j. prevetmed.2010.07.003 